\title{
Ein Beitrag zur Theorie des Schlafs.
}

Von

\section{Dr. Adolf Strümpell,}

Assistent an der med. Klinik zu Leipzig.

Im Herbst des vorigen Jahres 1876 wurde auf die medicinische Klinik zu Leipzig ein 16 jähriger Junge aufgenommen, bei welchem sich allmählich eine Anzahl von Sensibilitätsstörungen in soleher Ausdehnung entwickelte, wie sie nur äusserst selten zur Beobachtung kommt. Die Haut der gesanmten Körperoberfläche war fïr alle Qualitäten der Empfindung vollkommen anästhetisch. Die stärksten electrischen Ströme, eine brennende an die Haut gehaltene Kerze waren nicht im Stande, Schmerz oder auch nur eine Berïhrungsempfindung hervorzurufen. Die gleiche Anästhesie zeigten fast alle zugänglichen Schleimhäute des Körpers. Auch die unter dem Namen des „Muskelgefuihls" zusammengefassten Empfindungen fehlten durchaus. Der Kranke konnte bei geschlossenen Augen im Zimmer umhergetragen werden, seinen Gliedern konnten die unbequemsten Stellungen gegeben werden, ohne dass er eine Ahnung davon hatte. Selbst das Ermüdungsgefühl in den Mruskeln war verloren. D’azu kam aber noch eine vollständige Geschmacks- und Geruchslähmung, eine Amaurose des linken Auges und Taubheit des rechten Ohrs.

Man hatte es also, kurz gesagt, mit einem Individuum zu thun, welches mit der Aussenwelt nur noeh durch zwei Sinnespforten in Verbindung stand, durch sein eines (rechtes) Auge und sein eines (linkes) Ohr. Auch diese beiden letzten Pforten konnten leicht jederzeit versperrt und so die Folgen einer vollständigen Isolirung des Gehirns von allen äussern sensiblen Reizen beobachtet werden.

Ich habe diesen Versuch häufig gemacht, ihn oft Andern demonstrirt und stets mit demselben Erfolg. Wurde dem Kranken sein sehendes Auge verbunden und sein hörendes Ohr verstopft, so liessen nach wenigen (gewöhnlich 2-3) Minuten die anfänglichen Aeusserungen der Verwunderung und die unruhigen Be- 
wegungen nach, die Athmung wurde ruhig, regelmässig -- der Kranke war tief eingeschlafen. Mithin war hier die Möglichkeit realisirt, ein Individuum blos durch Abhaltung aller sensiblen Erregungen des Gehirns zu jeder Zeit künstlich sofort in Schlaf zu versetzen.

Interessant, wie das Einschläfern, war auch das Erwecken des Kranken. Nur durch einen Gehörsreiz z. B. einen Ruf in sein hörendes $\mathrm{Ohr}$ oder durch einen in sein sehendes Auge fallenden Lichtreiz, aber durch kein Rütteln und Schiitteln war er zu erwecken. Blos, wenn er sich selbst überlassen blieb, wachte er am Tage nach mehrstündigem Schlaf „von selbst" auf, sei es durch „innere Reize", sei es bei der zunehmenden Erregbarkeit des Gehirns durch geringe nicht zu vermeidende äussere Reize, welche seine noch funktionirenden Sinne trafen.

Die ausfithrliche Mittheilung des Falls wird an einem andern Orte erfolgen. Hier wollte ich nur auf Wunsch des Herrn Prof. Pflüger die Beobachtung des Einschlafens kurz mittheilen, deren nahe Beziehung zu der zuerst von Pflüger aufgestellten Theorie des Schlafs auf der Hand liegt. 